\title{
Correcting Positional Errors in Shore-Based Theodolite Measurements of Animals at Sea
}

\author{
Ophélie Sagnol, ${ }^{1}$ Femke Reitsma, ${ }^{2}$ Christoph Richter, ${ }^{3}$ and Laurence H. Field ${ }^{1}$ \\ ${ }^{1}$ School of Biological Sciences, University of Canterbury, Christchurch 8140, New Zealand \\ ${ }^{2}$ Department of Geography, University of Canterbury, Christchurch 8140, New Zealand \\ ${ }^{3}$ Department of Biology, University of Toronto at Mississauga, Mississauga, ON, Canada L5L 1C6 \\ Correspondence should be addressed to Ophélie Sagnol; ophelie.sagnol@hotmail.fr
}

Received 30 September 2013; Revised 3 December 2013; Accepted 9 December 2013; Published 22 January 2014

Academic Editor: Nobuyuki Miyazaki

Copyright (C) 2014 Ophélie Sagnol et al. This is an open access article distributed under the Creative Commons Attribution License, which permits unrestricted use, distribution, and reproduction in any medium, provided the original work is properly cited.

Determining the position of animals at sea can be particularly difficult and yet, accurate range and position of animals at sea are essential to answer a wide range of biological questions. Shore-based theodolite techniques have been used in a number of studies to examine marine mammal movement patterns and habitat use, offering reliable position measurements. In this study we explored the accuracy of theodolite measurements by comparing positional information of the same objects using two independent techniques: a shore-based theodolite station and an onboard GPS over a range of $25 \mathrm{~km}$ from the shore-based station. The technique was developed to study the habitat use of sperm whales (Physeter macrocephalus) off Kaikoura, New Zealand. We observed that the position accuracy fell rapidly with an increase in range from the shore-based station. Results showed that the horizontal angle was accurately determined, but this was not the case for the vertical angle. We calibrated the position of objects at sea with a regressionbased correction to fit the difference in distance between simultaneously recorded theodolite fixes and GPS positions. This approach revealed the necessity to calibrate theodolite measurements with objects at sea of known position.

\section{Introduction}

Knowing the accurate geographical position is essential for studying the spatial behaviour of animals at sea. Accurate positional data can answer a wide range of biological questions related to their movement patterns, habitat use, and the effects of human activities $[1,2]$.

A number of tracking methods can be used in order to obtain the position of animals at sea including recoverable data loggers, satellite tags [3-8], acoustic monitoring [9$12]$, and boat surveys [13-16]. All of these methods require expensive equipment, and time to collect data and the observer can be a source of potential disturbance [17]. As a result, the geographical coordinates of animals at sea are ideally determined from shore using a surveyor's theodolite, first introduced by Roger Paine in 1972 (Describe in Würsig et al. 1991) [18]. Shore-based theodolite tracking is a technique offering an inexpensive and nondisturbing alternative to other tracking techniques.
By tracking animals at sea from land, a small amount of equipment is required and a larger area can be monitored in a shorter amount of time compared to boat-based station. The theodolite readings (horizontal and vertical angle) can be converted into longitude and latitude when exact theodolite position and height above sea level are known [18, 19]. However, shore-based tracking can only occur with animals passing close enough to the coastline to be sighted from the shore-based station. Previous studies using theodolite tracking have focused on coastal species such as dolphins within $5 \mathrm{~km}$ from shore $[2,17,20,21]$. Shore-based tracking has also been used to monitor whales during their migration when their course passes close to shore [22-29] or to examine the effects of human activities on whales [30-34].

A number of parameters can influence the accuracy of the calculated position from theodolite fixes, such as the accuracy inherent to the theodolite, weather parameters (heat haze or swell), and the experience of the observer. One of the main 


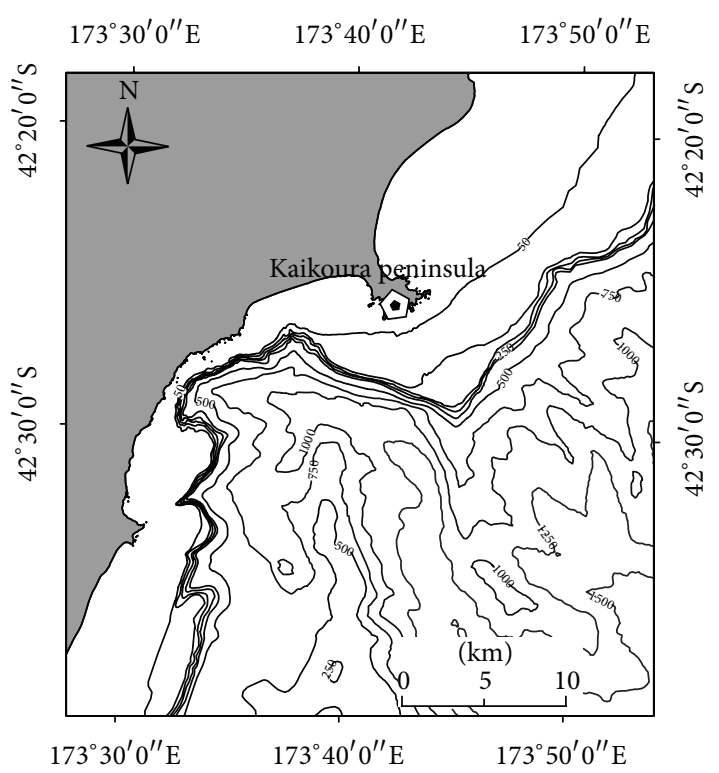

FIGURE 1: Bathymetry of the study area and location of the shorebased station (pentagon).

problems with shore-based theodolite data is the increasing error in positional fixes with increasing distance. In order to improve the accuracy of theodolite readings Würsig et al. [18] summarized several of the necessary elements to organize a shore-based study. Errors in the calculation of the station elevation will bias the calculations of the animal's position. Therefore, the theodolite station height should be greater than $45 \mathrm{~m}$ and errors in the elevation calculation should be within $\pm 10 \mathrm{~cm}$. Thus far, a better understanding of the calculation of the elevation has been the focus to improve theodolite accuracy $[18,35]$.

Previous boat-based platform studies have assessed the accuracy of distance measurements of animals at sea at close range $(0-2 \mathrm{~km})$ using video cameras and binoculars. Gordon [36] compared the photogrammetric technique with laser rangefinding binoculars and nondifferential GPS and determined that there was a good agreement for ranges measured between these three techniques. Kinzey and Gerrodette [37] identified the accuracy with which distances can be measured from ships using the reticles in binoculars at a range of $0-8 \mathrm{~km}$. They determined that the accuracy of distance measurements decreased with the distance of the object at sea [37]. Concerning shore-based tracking, Denardo et al. [1] established and calibrated a shore-based technique to measure interanimal spacing using a theodolite and a video camera over a $2 \mathrm{~km}$ range from the station.

In this paper, we compare positional information of the same objects from two independent techniques: a shorebased theodolite station and an onboard vessel GPS. By analysing how the difference in the positions from both techniques relates to the distance of the measured object from the shore-based station, we build a model to correct positions estimated from theodolite measurements. The objective of this study is mainly to describe a protocol that should be used when tracking animals at sea from a shore-based station.
This protocol will offer the possibility to easily correct the positional error arising in such shore-based data.

\section{Method}

The theodolite accuracy correction was developed for a sperm whale (Physeter macrocephalus) habitat study within the Kaikoura submarine canyon in New Zealand. The proximity of the Kaikoura submarine canyon to the coast of the South Island makes it one of the few places in the world where male sperm whales are found close to the shoreline $[38,39]$, offering the opportunity to track sperm whales from shore. A shore-based station was set up on a hill situated at the east end of the Kaikoura peninsula $\left(42^{\circ} 25^{\prime} 47.1^{\prime \prime} \mathrm{S}\right.$, $\left.173^{\circ} 41^{\prime} 54.6^{\prime \prime} \mathrm{E}\right)$ (Figure 1$)$ at a height of $99.88 \mathrm{~m}( \pm 0.04 \mathrm{~m})$ above sea level (method described by Würsig et al. [18]). This location provided a good vantage point overlooking the study area encompassing the Kaikoura canyon and surrounding nearshore habitat.

\section{Data Collection}

To determine the theodolite's accuracy, we needed independently derived and accurate geographical positions of the same objects taken at the same time as recorded by the shore-based theodolite station. During our study, two research boats were operating inside our study area. One of the research vessels was a $6 \mathrm{~m}$ aluminium monohull used for behavioural and acoustic observation on sperm whales. The second vessel was a $5.5 \mathrm{~m}$ rigid-hull inflatable vessel used for a study on dusky dolphins (Lagenorhynchus obscurus). Both vessels were equipped with a GPS (accuracy within $3 \mathrm{~m}$ ) and recorded the vessel's position every 15 seconds. From shore, we collected the positions of these research vessels using a Sokkia Set 4000 theodolite (accuracy of angle measurement $\pm 5^{\prime \prime}$ and measuring time less than $0.5 \mathrm{sec}$ ). For consistency, we fixed the boat positions by placing the theodolite crosshair at the waterline at the centre of the vessel. We connected the theodolite to a laptop running the tracking program Pythagoras [19]. The software transformed real-time theodolite readings into GPS coordinates corrected for curvature of the Earth and tide level and stored them for analysis [19].

\section{Results}

During the study period we recorded a total of 347 theodolite fixes of research vessels (Table 1 ). The positions recorded were between $2 \mathrm{~km}$ and up to $26 \mathrm{~km}$ from the theodolite station (Table 1) and were distributed along the whole study area (Figure 2). For each research vessel position recorded with the theodolite, we extracted the time related position recorded with the vessels' onboard GPS.

We compared vessel positions based on theodolite readings with the time-related positions extracted from the vessels' onboard GPS (Figure 3). Theodolite and GPS positions appeared to be on the same line as seen from the theodolite station when viewing from plan view (Figure 4(a)). 


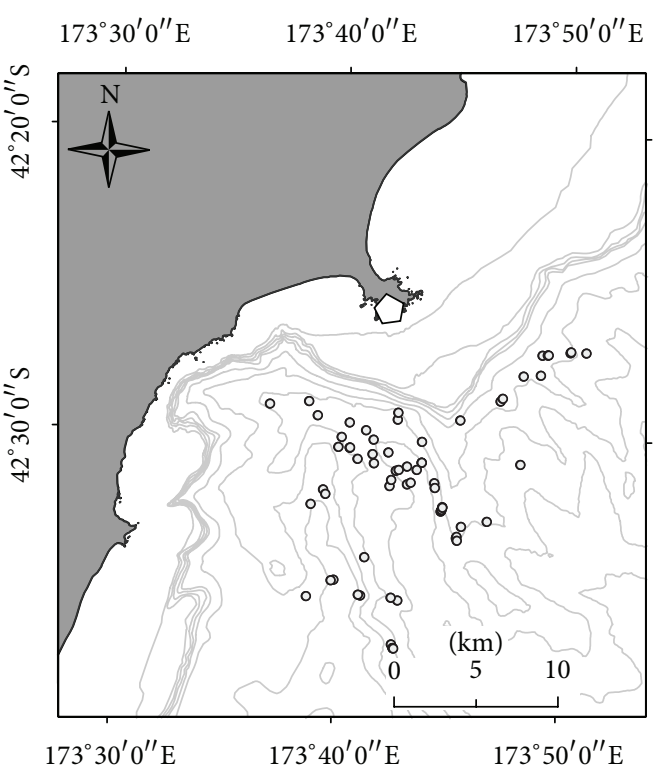

(a)

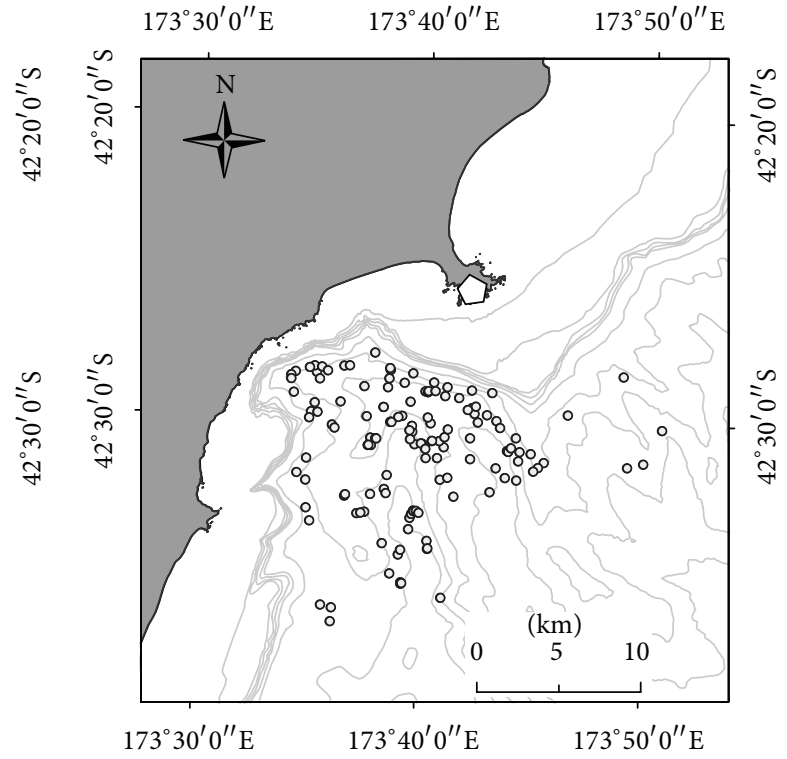

(b)

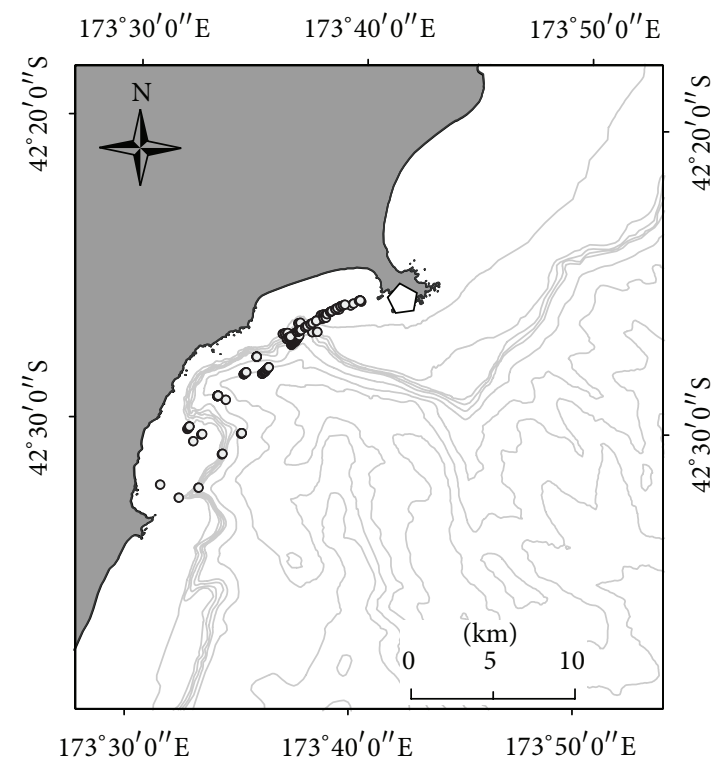

(c)

FIGURE 2: Research vessels locations recorded by onboard GPS by year. (a) and (b) are fixes from the sperm whale research vessel (2010 and 2011) and (c) is fixes from the dolphin research vessel (2012) (pentagon: shore-based station, grey dot: research vessel positions).

However, when seen from the side, theodolite and GPS positions differed (Figure 4(b)). We hypothesized that while horizontal angles recorded with the theodolite were accurate, vertical angles were inaccurately determined. We investigated this hypothesis by separately examining the relationships between horizontal and vertical angles measured by GPS and theodolite.

To compare the accuracy, all theodolite fixes and onboard GPS positions were converted to a Cartesian system using the tool "calculate geometry" in ArcGIS 10.1. We also converted the geographic coordinates of the theodolite station in order to centre all the positions with the theodolite station. In order to calculate an angle towards a given position, we made use of the fact that we know the length of the vertical distance ( $y$ is latitude converted to the Cartesian system) and the horizontal distance ( $x$ is longitude converted to the Cartesian system) to this position.

The horizontal angle $\left(\theta_{H}\right)$ to the research boat position (GPS) or theodolite position (TH) can be calculated using the relationship

$$
\tan \left(\theta_{H-\mathrm{GPS}}\right)=y_{\mathrm{GPS}} / x_{\mathrm{GPS}}
$$$$
\tan \left(\theta_{\mathrm{H}-\mathrm{TH}}\right)=y_{\mathrm{TH}} / x_{\mathrm{TH}} \text {. }
$$

The vertical angle $\left(\theta_{V}\right)$ to the research boat position (GPS) or theodolite position (TH) can be calculated using the 


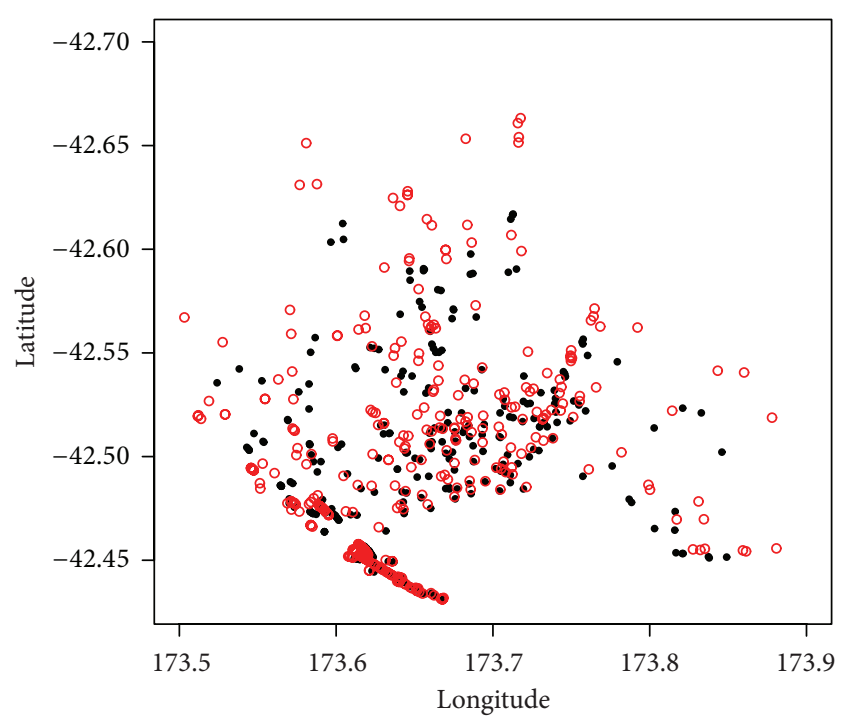

FIGURE 3: Comparison of all research vessel positions over all years recorded by theodolite (red dots) and by onboard GPS (black dots).

TABLE 1: Distance summary of the two research vessels from the theodolite station $( \pm \mathrm{SE})$.

\begin{tabular}{lccc}
\hline & \multicolumn{2}{c}{$\begin{array}{c}\text { Sperm whale research } \\
\text { vessel positions }\end{array}$} & $\begin{array}{c}\text { Dolphin } \\
\text { research vessel } \\
\text { positions }\end{array}$ \\
& $\begin{array}{c}2010 \\
(N=66)\end{array}$ & $\begin{array}{c}2011 \\
(N=137)\end{array}$ & $2012(N=144)$ \\
\hline $\begin{array}{l}\text { Mean distance } \\
(\mathrm{km})\end{array}$ & $12.99( \pm 0.74)$ & $11.93( \pm 0.39)$ & $7.93( \pm 0.28)$ \\
$\begin{array}{l}\text { Maximum distance } \\
(\mathrm{km})\end{array}$ & 25.85 & 25.22 & 18.52 \\
$\begin{array}{l}\text { Minimum distance } \\
(\mathrm{km})\end{array}$ & 2.96 & 4.76 & 2.45 \\
\hline
\end{tabular}

relationship using the distance from the position $(D)$ and the theodolite station height $(h)$ :

$$
\tan \left(\theta_{V-\mathrm{GPS}}\right)=D_{\mathrm{GPS}} / h=\left(y_{\mathrm{GPS}} / \cos \left(\theta_{H-\mathrm{TH}}\right)\right) / h,
$$$$
\tan \left(\theta_{V-\mathrm{TH}}\right)=D_{\mathrm{TH}} / h=\left(y_{\mathrm{TH}} / \cos \left(\theta_{H-\mathrm{TH}}\right)\right) / h \text {. }
$$

The error in distance $(\Delta D)$ is given by subtracting the distances recorded from the GPS positions $\left(D_{\mathrm{GPS}}\right)$ and the distances recorded from the theodolite $\left(D_{\mathrm{TH}}\right)$ :

$$
\Delta D=D_{\mathrm{TH}}-D_{\mathrm{GPS}} .
$$

We then determined the distance of the object at sea. As expected, $D$ differed significantly between theodolite and onboard GPS positions (Mann Whitney $U$ test, $P=0.013$ ). While the $\theta_{H}$ is resolved very accurately with the theodolite (Mann Whitney $U$ test, ns), $\theta_{V}$ is not (Mann Whitney $U$ test, $P=0.013)$.

Since distance from the platform can influence accuracy of theodolite readings, we examined the relationship between distance from shore and the distance error between simultaneously recorded theodolite fixes and GPS positions (Figure 5). We tested a couple of models to determine the best fitted model and we used the Akaike Information Criterion
TABLE 2: Results of models analyses (AIC = Akaike Information

\begin{tabular}{|c|c|c|}
\hline Model & AIC & $\Delta \mathrm{AIC}$ \\
\hline$y \sim a * x \wedge b$ & 5138.896 & $\mathbf{0}$ \\
\hline$y \sim x * b$ & 5502.441 & 363.545 \\
\hline$y \sim x+b$ & 6722.799 & 1583.903 \\
\hline$y \sim x$ & 5267.642 & 128.746 \\
\hline$y \sim-1+x$ & 5502.441 & 363.545 \\
\hline
\end{tabular}
Criterion; $\left.\Delta_{i}(\mathrm{AIC})=\mathrm{AIC}_{i}-\min \mathrm{AIC}\right)$.

(AIC) to select the best model. A quadratic model of the form $y=a * x \wedge b$ fitted the data best (Table 2) and we plotted the best curve fitting for visualization (Figure 5).

The best model $(y \sim a * x \wedge b)$ was used to correct theodolite fixes based on their distance from the theodolite station. After applying this correction to our data, the vertical angles of the theodolite fixes did not differ from the GPS positions (Mann Whitney $U$ test, ns). After calibration, theodolite positions did not differ from GPS positions anymore (Figure 6, Mann Whitney $U$ test, ns).

The corrected positions showed normal distributions of errors in distance suggesting no evidence of overall bias in distance after the correction (Figure 7).

\section{What Is Influencing This Error?}

A number of parameters can influence the accuracy of theodolite positions, such as the observer experience, the size of the boat, incorrect calibration, imprecision in measuring the theodolite height above sea level (waves, swell, and tidal estimation) and the refraction [36, 37].

We illuminated the possibility of an error coming from an imprecision in measuring the height of the shore-based station. In order to avoid such an error we determined the height of the theodolite station twice during our study. We also checked the height of the theodolite eyepieces during the day to make sure that it did not vary. To determine the possible effect of the observers on the theodolite fixes, we modelled separately the error with distance depending on the year. During 2010, different people collected the data through the year and data collected from mid-2011 and 2012 were entirely collected by the same observer. By comparing the distance error on the annual dataset with the general distance error on the whole dataset we could assess whether experienced versus inexperienced observer influenced the accuracy in theodolite fixes. We hypothesized that a presence of observer bias will be described by a better accuracy of theodolite fixes towards the end of the fieldwork. However, there was no significant difference in the theodolite fixes corrected by years or corrected using the complete database (Mann Whitney $U$ test, ns). We also compared the error in distance from data collected from the same observer with the distance error in the whole dataset and there was no significant difference (Mann Whitney $U$ test, ns). After these analyses we determined that, in our study, the observer did not significantly influence the accuracy of theodolite fixes. 


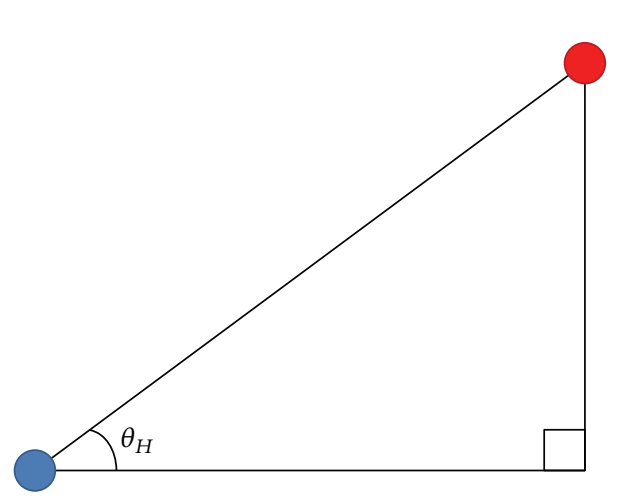

(a)

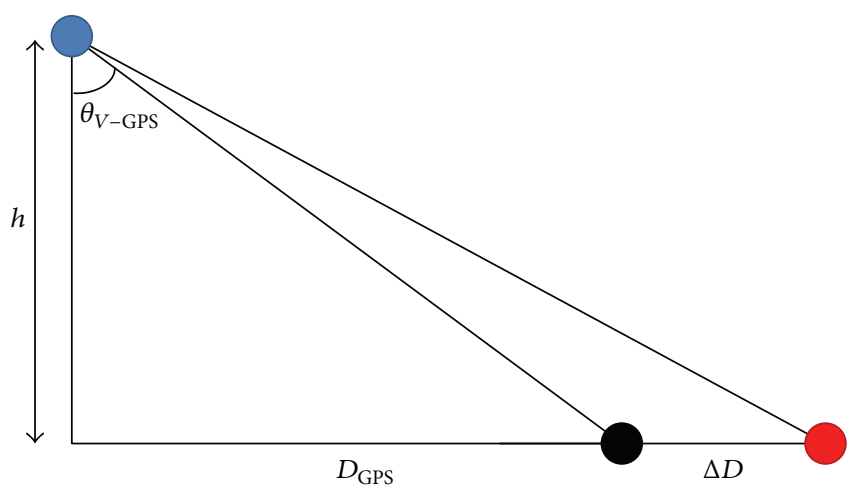

(b)

FIGURE 4: (a) Plan view and (b) side view schematic for the GPS position of a particular position recorded by the theodolite (red dot) compared to the position collected with the onboard GPS (black dot) extracted from Figure 3. The blue dot is the shore-based station.

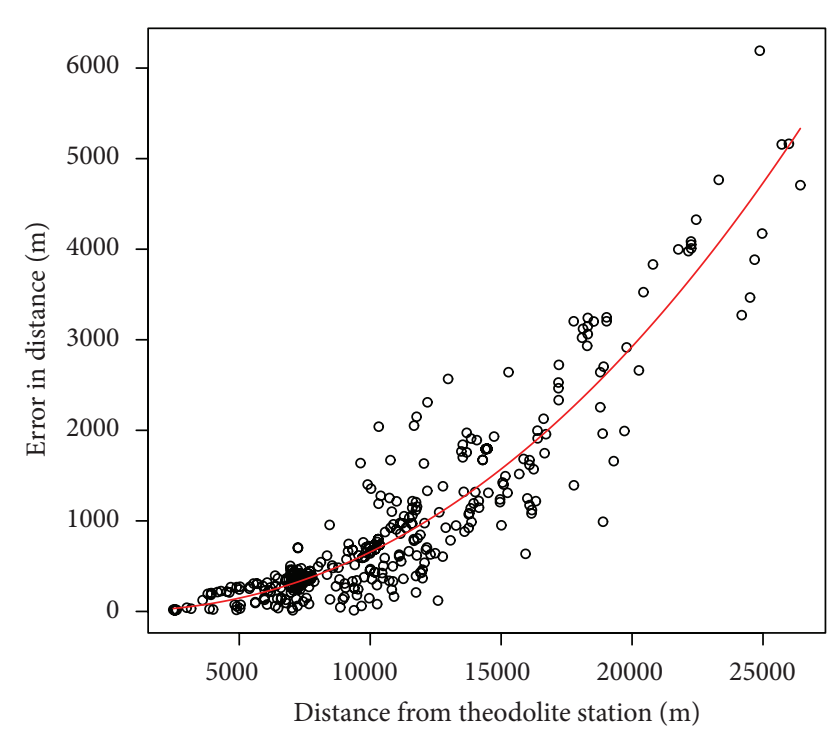

FIGURE 5: Error in measurements of distance between theodolite fixes and GPS positions. Red line: best fitting curve $(y \sim a * x \wedge b)$.

We then looked at the possible impact of the size of the object being tracked. Analysis showed that there was no significant influence of the boat size on the fixes accuracy (Mann Whitney $U$ test, ns). Therefore, neither observer experience nor object size influenced accuracy of theodolite positions.

Because data were collected from a shore-based station, it was not possible to obtain accurate values for the swell height and the Beaufort sea state. Data were collected only during favourable weather conditions, limiting the effect of swell and Beaufort sea state on research vessels/sperm whales detection. Consequently, it was unlikely that these conditions influenced our results.

The possibility of an error in positioning the theodolite crosshair on the waterline can be one of the factors causing an overestimation of the distance from the shore-based station. Since size of the object will decrease with the distance, it

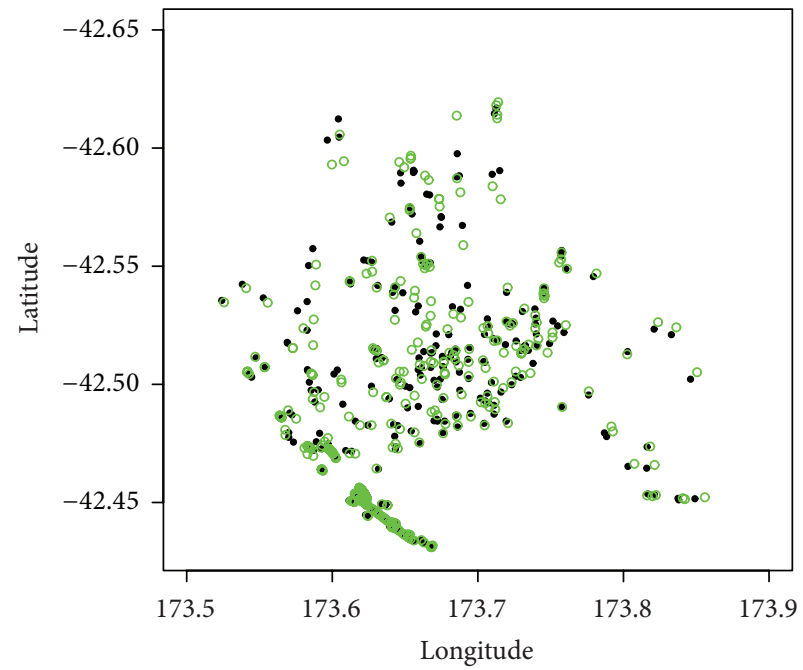

FIGURE 6: Comparison of the corrected positions of the research vessel over all years recorded by theodolite (green dots) and by onboard GPS (black dots).

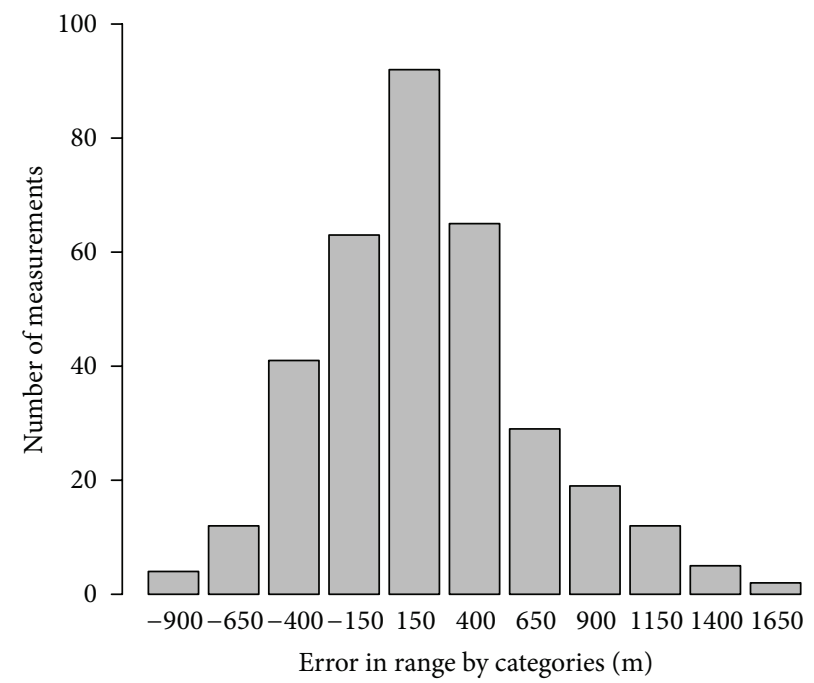

FiguRE 7: Distribution of $\Delta D$ after correction. 
became increasingly difficult for the observer to establish the position of the object waterline. In addition, the size of the theodolite crosshair remained constant, covering up distant and thus small objects, making it difficult to accurately locate the waterline. Therefore the error can come from the difficulty by the observer to accurately position the theodolite crosshair on the waterline which leads to an error that increases with distance.

\section{Discussion}

This study presented the accuracy in determining the position of object at sea using a surveyor theodolite over a distance range of $25 \mathrm{~km}$ from the shore-based station. Our results indicated that the model we provided can successfully correct the positional error in shore-based theodolite measurements of animals at sea.

The particularity of this study was to focus on objects found at large distance from the shore-based station. The accuracy and precision of determining the distance of objects at sea has been previously studied for a range up to $8 \mathrm{~km}$ from the shore $[1,36,37]$. Studies using a surveyor theodolite for marine mammals tracking avoided collecting data at large distances because of the likelihood of inaccuracy in the distance estimation. These studies limited their data collection to a critical distance from the theodolite station in order to ensure consistent data $[1,26,27,40]$. By having known GPS positions over the whole study area we significantly improved our theodolite measurements and this allowed us to collect data to the limit of the visual capacity. The method presented here could easily be used in other locations in order to accurately survey a larger study area from a shore-based station.

Theodolite estimation has been shown to be biased by the observer experiences. Our results showed that this factor was not significantly influencing the error. Our observers were trained before the fieldwork and one main observer was in charge of most of the theodolite data collection.

Previous studies found that the swell and Beaufort sea state were important factors influencing the accuracy of distance estimates for sightings of marine mammals [37, 41]. In our case, it was not possible to access a database providing information on swell and Beaufort sea state. We looked at the year effect and it was not statistically significant in our model, which suggests that the weather factors did not explain the bias in overestimation of the theodolite measurements.

The effect of refraction was not directly tested during our study. Light does not travel in straight lines; when light travels through the Earth's atmosphere, it is subject to refraction. Mirages and other refraction events are the result of the bending of rays in the Earth's atmosphere. For range measurement studies the effect of refraction will result in an angular error and the distance estimates of distant objects will be seriously affected. Several studies integrated a correction for the refraction for surveys using binoculars and video camera $[36,37,42]$ based on the air temperature and pressure measured daily during their data collection. If the range measurements are not corrected with the refraction correction, distances will be negatively biased. In our results, the error increase with the distance, rejecting the possibility of an impact caused by the refraction. In addition, by regularly collecting the position of an object at known range during fieldwork all the parameters influencing the error can be corrected.

Optical errors can be an important factor in theodolite accuracy and can be affected by the fact that theodolite scopes are composed of a monocular scope with a single eyepiece. Therefore, it is harder to see the object due to the decreasing field of view, increasing the possibility of an optical error. Parallax error was also considered when positioning the theodolite crosshair. This error is caused by a change in the position of the eye which will change the point of aim of the scope. If the parallax error was important it should influence both vertical and horizontal angles and should differ between observers and days. However, in our study we determined that the horizontal angle was accurately determined by the theodolite.

The last and more probable error came from the crosshair positioning error. This study showed that the observer was able to accurately determine the general position of the object, described with an accurate horizontal angle, but what appeared to be difficult was to establish the exact vertical angle, the position where the object met the waterline. As the object became smaller with distance, it was harder for the observer to define the waterline. Moreover, the large size of the theodolite crosshair made it difficult to position it on small objects. In conclusion, with increasing distance, observers tended to place the theodolite crosshair on the object instead of on the waterline, creating a bias in the positioning crosshair. Positioning the crosshair on the object rather than the waterline will overestimate the distance and may cause the positive bias in distance estimation we observed.

During our study it was not possible to have constant objects found at different distances within our study area and collecting opportunistic vessel positions was the only approach to estimate positional error. Thus, the protocol we propose could be improved by using objects at constant positions, such as buoys. The difficulty will be to have enough such objects across the study area.

\section{Conclusion}

This study revealed the necessity of calibrating theodolite measurements when tracking animals at sea. Known GPS positions of objects within the study area should be used in all theodolite studies in order to correct the error with distance. One of the most important applications of this technique is its potential to improve the use of shore-based stations for habitat and abundance studies at the limit of visual detection.

\section{Conflict of Interests}

The authors declare that there is no conflict of interests regarding the publication of this paper. 


\section{Acknowledgments}

Equipment was provided by the Department of Conservation, New Zealand. The authors thank Dara Orbach and Manuel C. Fernandes who provided the data from the onboard GPS. They are grateful to the many volunteers that have given their time to this project. Finally, they also thank Kathy Walter from the National Institute of Water and Atmosphere Research (NIWA) who provided data on tide levels.

\section{References}

[1] C. Denardo, M. Dougherty, G. Hastie, R. Leaper, B. Wilson, and P. M. Thompson, "A new technique to measure spatial relationships within groups of free-ranging coastal cetaceans," Journal of Applied Ecology, vol. 38, no. 4, pp. 888-895, 2001.

[2] H. Bailey and P. Thompson, "Quantitative analysis of bottlenose dolphin movement patterns and their relationship with foraging," Journal of Animal Ecology, vol. 75, no. 2, pp. 456-465, 2006.

[3] M. Amano and M. Yoshioka, "Sperm whale diving behavior monitored using a suction-cup-attached TDR tag," Marine Ecology Progress Series, vol. 258, pp. 291-295, 2003.

[4] M. P. Heide-Jorgensen, E. S. Nordoy, N. Oien et al., "Satellite tracking of minke whales (Balaenoptera acutorostrata) off the coast of northen Norway," Journal of Cetacean Research \& Management, vol. 3, no. 2, pp. 175-178, 2001.

[5] W. A. Watkins, M. A. Daher, N. A. Dimarzio et al., "Sperm whale surface activity from tracking by radio and satellite tags," Marine Mammal Science, vol. 15, no. 4, pp. 245-267, 1999.

[6] G. L. Kooyman, Diverse Divers: Physiology and Behavior, Springer, New York, NY, USA, 1989.

[7] M. A. Hindell, D. J. Slip, and H. R. Burton, "The diving behaviour of adult male and female southern elephant seals, Mirounga leonina (Pinnipedia: Phocidae)," Australian Journal of Zoology, vol. 39, no. 5, pp. 595-619, 1991.

[8] R. L. DeLong, B. S. Stewart, and R. D. Hill, "Documenting migrations of northern elephant seals using day length," Marine Mammal Science, vol. 8, pp. 155-159, 1992.

[9] M. R. Heupel, J. M. Semmens, and A. J. Hobday, "Automated acoustic tracking of aquatic animals: scales, design and deployment of listening station arrays," Marine and Freshwater Research, vol. 57, no. 1, p. 113, 2006.

[10] S. M. Wiggins and J. A. Hildebrand, "High-frequency Acoustic Recording Package (HARP) for broad-band, long-term marine mammal monitoring," in International Symposium on Underwater Technology and Workshop on Scientific Use of Submarine Cables and Related Technologies, pp. 551-557, April 2007.

[11] W. A. Watkins and W. E. Schevill, "Sperm whale codas," Journal of the Acoustical Society of America, vol. 62, no. 6, pp. 1485-1490, 1977.

[12] K. M. Stafford, C. G. Fox, and D. S. Clark, "Long range detection and localization of blue whale calls in the northeast Pacific using military hydrophone arrays," Journal of the Acoustical Society of America, vol. 104, no. 6, pp. 3616-3625, 1998.

[13] L. T. Ballance, "Habitat use patterns and ranges of the bottlenose dolphin in the Gulf of California, Mexico," Marine Mammal Science, vol. 8, no. 3, pp. 262-274, 1992.

[14] A. Cañadas, R. Sagarminaga, and S. García-Tiscar, "Cetacean distribution related with depth and slope in the Mediterranean waters off southern Spain," Deep-Sea Research, vol. 49, no. 11, pp. 2053-2073, 2002.

[15] M. C. Ferguson, J. Barlow, S. B. Reilly, and T. Gerrodette, "Predicting Cuvier's (Ziphius cavirostris) and Mesoplodon beaked whale population density from habitat characteristics in the eastern tropical Pacific Ocean," Journal of Cetacean Research and Management, vol. 7, no. 3, pp. 287-299, 2006.

[16] G. D. Hastie, R. J. Swift, G. Slesser, P. M. Thompson, and W. R. Turrell, "Environmental models for predicting oceanic dolphin habitat in the Northeast Atlantic," ICES Journal of Marine Science, vol. 62, no. 4, pp. 760-770, 2005.

[17] K. Barr and E. Slooten, "Effects of tourism on dusky dolphins at Kaikoura," New Zealand Journal of Marine and Freshwater Research, vol. 35, pp. 277-287, 1999.

[18] B. Würsig, F. Cipriano, and M. Würsig, "Dolphin movement patterns: information from radio and theodolite tracking studies," in Dolphin Societies: Discoveries and Puzzles, K. Pryor and K. S. Norris, Eds., pp. 79-111, University of California Press, Berkeley, Calif, USA, 1991.

[19] G. A. Gailey and J. Ortega-Ortiz, "A note on a computer-based system for theodolite tracking of cetaceans," Journal of Cetacean Research \& Management, vol. 4, no. 2, pp. 213-218, 2002.

[20] S. Harzen, "Use of an electronic theodolite in the study of movements of the bottlenose dolphin (Tursiops truncatus) in the Sado Estuary, Portugal," Aquatic Mammals, vol. 28, no. 3, pp. 251-260, 2002.

[21] T. Photopoulou, P. B. Best, P. S. Hammond, and K. P. Findlay, "Movement patterns of coastal bottlenose dolphins in the presence of a fast-flowing, prevailing current: shore-based observations at Cape Vidal, South Africa," African Journal of Marine Science, vol. 33, no. 3, pp. 393-401, 2011.

[22] N. J. Patenaude, Southern Right Whales Wintering in the Auckland Islands, vol. 321 of Conservation Advisory Science Notes, Department of Conservation, Wellington, New Zealand, 2000.

[23] P. B. Best, K. Sekiguchi, and K. P. Findlay, "A suspended migration of humpback whales Megaptera novaeangliae on the west coast of South Africa," Marine Ecology Progress Series, vol. 118, no. 1-3, pp. 1-12, 1995.

[24] M. E. Morete, A. Freitas, M. H. Engel, R. M. Pace III, and P. J. Clapham, "A novel behavior observed in humpback whales on wintering grounds at Abrolhos Bank (Brazil)," Marine Mammal Science, vol. 19, no. 4, pp. 694-707, 2003.

[25] A. Schaffar, B. Madon, C. Garrigue, and R. Constantine, "Avoidance of whale watching boats by humpback whales in their main breeding ground in New Caledonia," SC/61/WW/6 Paper SC/34/WW6, IWC Scientific Committee, 2009.

[26] K. P. Findlay, P. B. Best, and M. A. Meÿer, "Migrations of humpback whales past Cape Vidal, South Africa, and an estimate of the population increase rate (1988-2002)," African Journal of Marine Science, vol. 33, no. 3, pp. 375-392, 2011.

[27] T. K. Boye, M. Simon, and P. T. Madsen, "Habitat use of humpback whales in Godthaabsfjord, West Greenland, with implications for commercial exploitation," Journal of the Marine Biological Association of the United Kingdom, vol. 90, pp. 15291538, 2010.

[28] J. Barendse, P. B. Best, M. Thornton, C. Pomilla, I. Carvalho, and H. C. Rosenbaum, "Migration redefined? seasonality, movements and group composition of humpback whales megaptera novaeangliae off the west coast of South Africa," African Journal of Marine Science, vol. 32, no. 1, pp. 1-22, 2010.

[29] M. E. Morete, T. L. Bisi, R. M. Pace III, and S. Rosso, "Fluctuating abundance of humpback whales (Megaptera novaeangliae) in 
a calving ground off coastal Brazil," Journal of the Marine Biological Association of the United Kingdom, vol. 88, no. 6, pp. 1229-1235, 2008.

[30] G. Gailey, B. Würsig, and T. L. McDonald, "Abundance, behavior, and movement patterns of western gray whales in relation to a 3-D seismic survey, Northeast Sakhalin Island, Russia," Environmental Monitoring and Assessment, vol. 134, no. 1-3, pp. 75-91, 2007.

[31] D. W. Funk, T. M. Markowitz, and R. R. Rodrigues, Eds., Baseline Studies of Beluga Whale Habitat Use in Knik Arm, Upper Cook Inlet, Alaska, 2004-2005, LGL Alaska Research Associates, HDR, for the Knik Arm Bridge and Toll Authority, Department of Transportation and Public Facilities, and the Federal Highway Administration, Anchorage, Alaska, USA, 2005.

[32] T. M. Markowitz and T. L. McGuire, Temporal-Spatial Distribution, Movements and Behavior of Beluga Whales Near the Port of Anchorage, Alaska, Alaska Research Associates, for Integrated Concepts and Research Corporation and the U.S. Department of Transportation Maritime Administration, Anchorage, Alaska, USA, 2007.

[33] D. Lundquist, M. Sironi, B. Würsig, and V. Rowntree, "Behavioral responses of southern right whales to simulated swimwith-whale tourism at Península Valdés, Argentina," Journal of Cetacean Research \& Management, SC/60/WW4, 2006.

[34] F. Ollervides, Effects of boat traffic on the behavior of gray whales, Eschrichtius robustus, in Bahia Magdalena, Baja California Sur, Mexico [M.S. thesis], Texas A\&M University, 1997.

[35] H. Bailey and D. Lusseau, "Increasing the precision of theodolite tracking: modified technique to calculate the altitude of landbased observation sites," Marine Mammal Science, vol. 20, no. 4, pp. 880-885, 2004.

[36] J. Gordon, "Measuring the range to animals at sea from boats using photographic and video images," Journal of Applied Ecology, vol. 38, no. 4, pp. 879-887, 2001.

[37] D. Kinzey and T. Gerrodette, "Distance measurements using binoculars from ships at sea: accuracy, precision and effects of refraction," Journal of Cetacean Research \& Management, vol. 5, no. 2, pp. 159-171, 2003.

[38] J. Gordon, R. Leaper, F. G. Hartley, and O. Chappell, "Effects of whale-watching vessels on the surface and underwater acoustic behaviour of sperm whales off Kaikoura, New Zealand," Sciences and Research Series 52, Department of Conservation, Wellington, New Zealand, 1992.

[39] N. Jaquet, S. Dawson, and E. Slooten, "Seasonal distribution and diving behaviour of male sperm whales off Kaikoura: foraging implications," Canadian Journal of Zoology, vol. 78, no. 3, pp. 407-419, 2000.

[40] R. Williams, A. W. Trites, and D. E. Bain, "Behavioural responses of killer whales (Orcinus orca) to whale-watching boats: opportunistic observations and experimental approaches," Journal of Zoology, vol. 256, no. 2, pp. 255-270, 2002.

[41] J. Barlow, T. Gerrodette, and J. Forcada, "Factors affecting perpendicular sighting distances on shipboard line-transect surveys for cetaceans," Journal of Cetacean Research and Management, vol. 3, no. 2, pp. 201-212, 2001.

[42] R. Leaper and J. Gordon, "Application of photogrammetric methods for locating and tracking cetacean movements at sea," Journal of Cetacean Research and Management, vol. 3, no. 2, pp. 131-141, 2001 

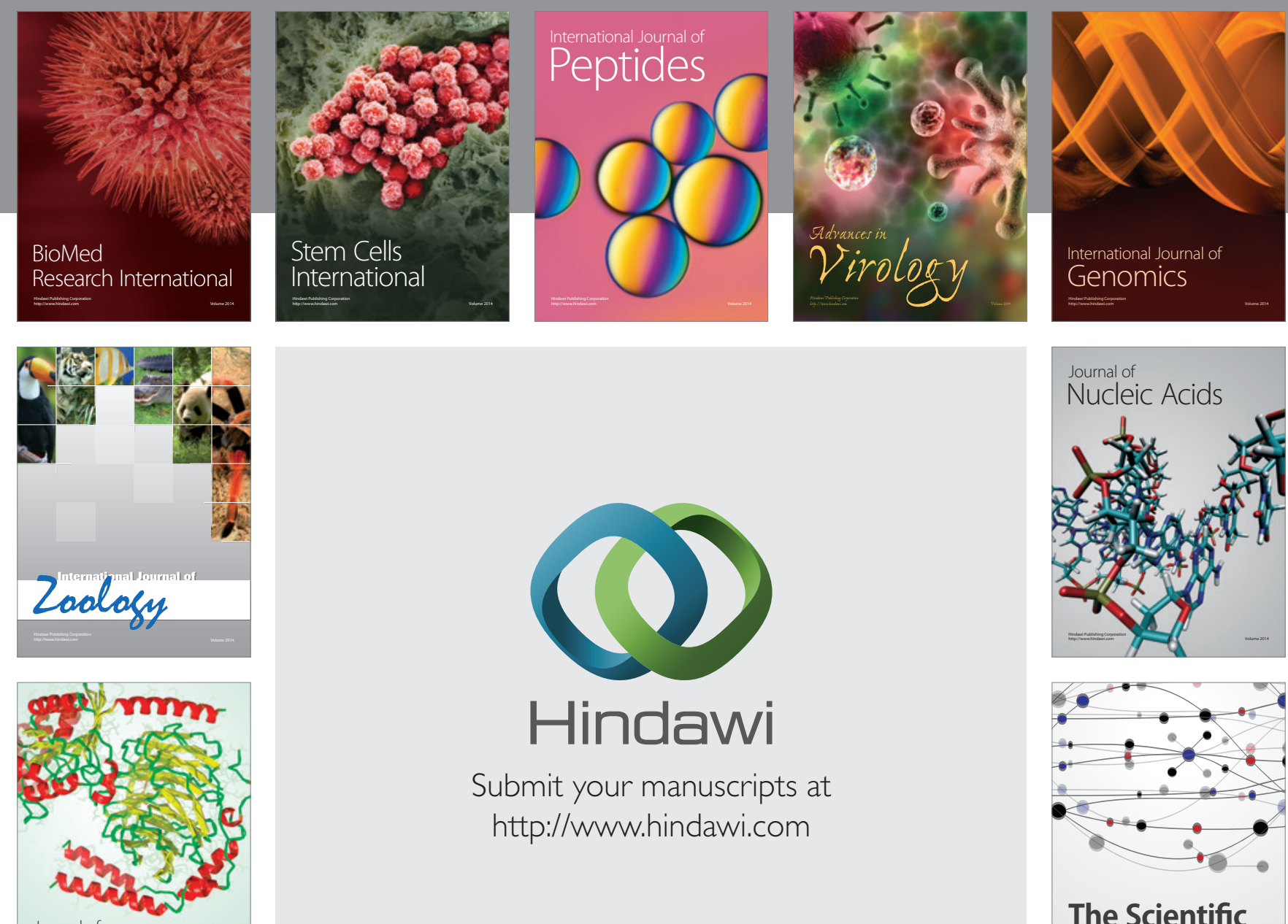

Submit your manuscripts at

http://www.hindawi.com

Journal of
Signal Transduction
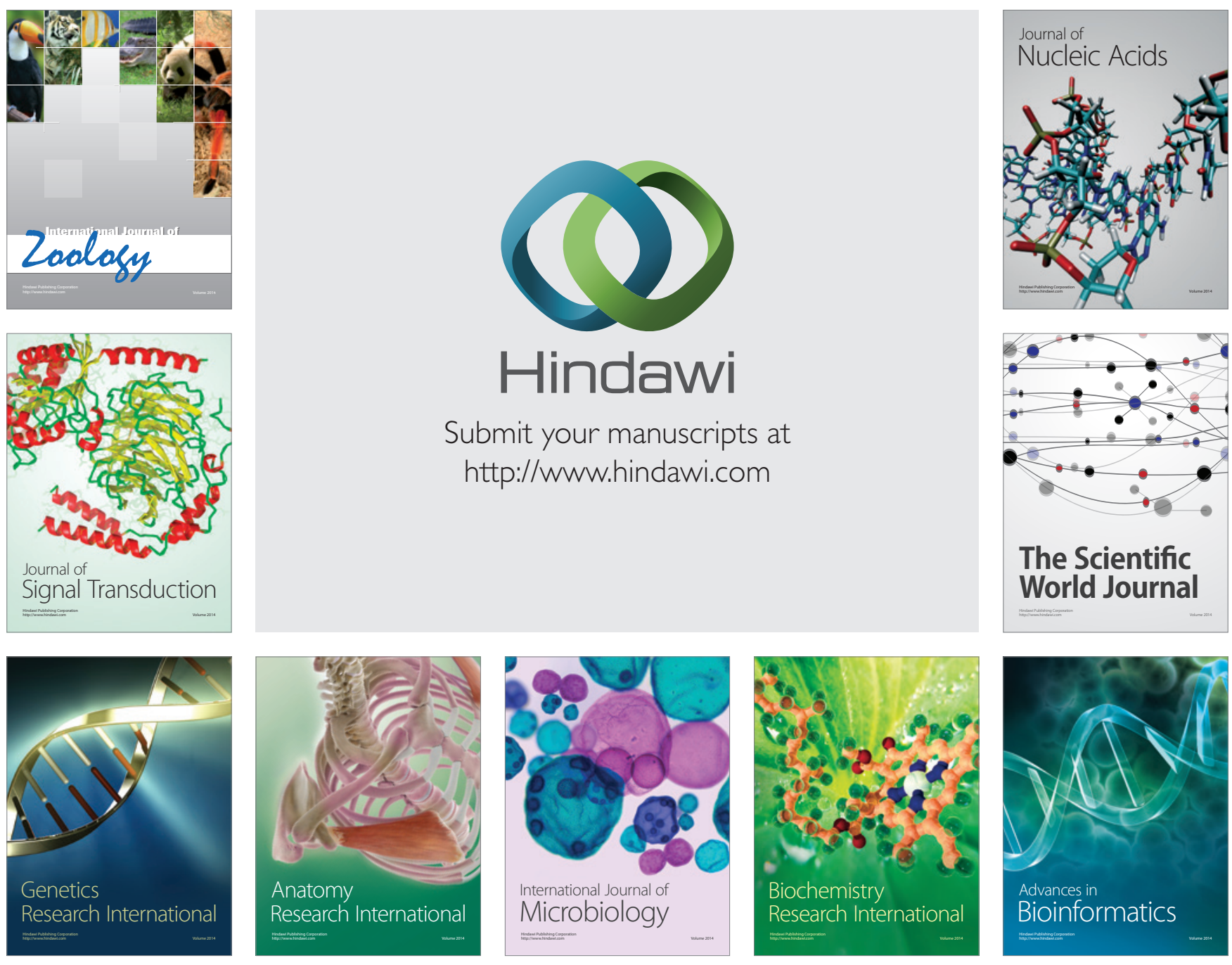

The Scientific World Journal
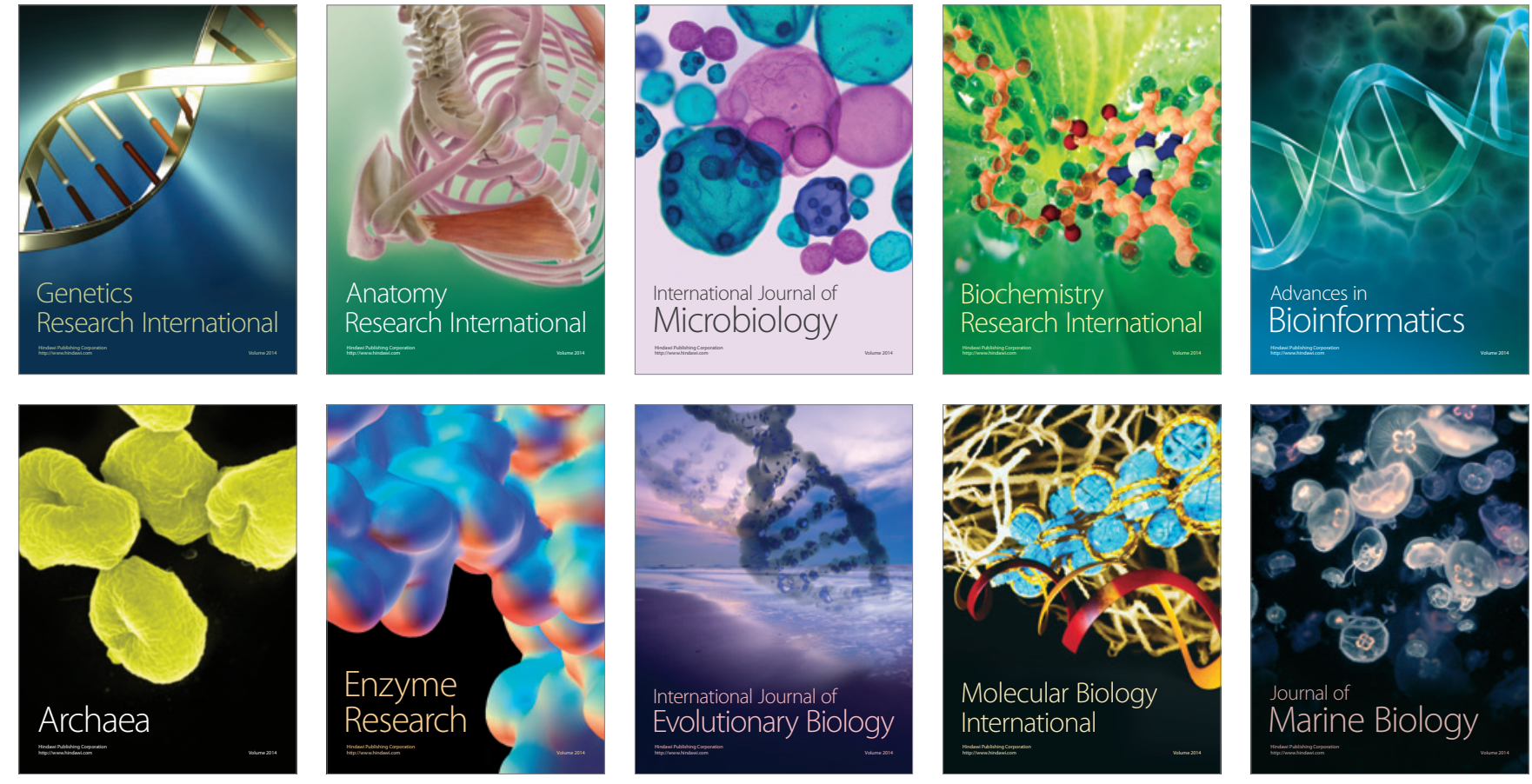